Article

\title{
E-Government Maturity Model for Sustainable E-Government Services from the Perspective of Developing Countries
}

\author{
Pusp Raj Joshi and Shareeful Islam * (D) \\ School of Architecture, Computing and Engineering, University of East London, London E162RD, UK; \\ pusp.joshi@uel.ac.uk \\ * Correspondence: shareeful@uel.ac.uk; Tel.: +44-208-223-7273
}

Received: 11 April 2018; Accepted: 18 May 2018; Published: 5 June 2018

\begin{abstract}
Electric government (e-government) projects in developing countries are facing many challenges to deliver sustainable e-government services. From the existing literature, we found that most of the studies considered lack of technology, and limitations in budgets and human resources as the main hurdles in effective implementation of e-government services. Along with these limitations, we found that the e-government maturity models adopted by developing countries are failing to provide an appropriate strategic plan to deploy sustainable e-government services. While assessing the existing e-government maturity model, we made several observations on the lack of detail, the technology-centric nature, the emphasis on implementation, and the lack of an adoption strategy. This work contributes toward the proposition of a new e-government maturity model that would address the limitations of exiting e-government maturity models, and would support governments in developing countries to achieve sustainable e-government services. To achieve this goal, we considered five determinants-a detailed process, streamlined services, agile accessibility, use of state-of-the-art technology, and trust and awareness. The proposed model was validated by employing an empirical investigation through case-study and survey methods. We found that both the implementers (government) and adopters (users) of the e-government services benefited from the proposed model, resulting in an increased sustainability of e-government services.
\end{abstract}

Keywords: e-government; e-government maturity model; sustainable e-government services; trust; awareness; adoption; determinants

\section{Introduction}

The adoption and use of electronic government (e-government) services in developing countries is still a big issue. A digital divide among the people, poorly offered e-government services, and availability and access to the technology by the people are some of the critical issues faced with e-government projects. Although occurrences of these issues in the developing countries are inevitable, if appropriate measures are taken when designing e-government projects, governments would be able to achieve wider participation from stakeholders in e-government activities. The design of e-government projects is driven by e-government maturity models, which are often called stage models. A maturity model is a conceptual framework that outlines how e-government projects should be assimilated in stages [1,2]. Considering the enormity and complexity of electronic government projects, it is often assimilated in stages [3]. Several efforts have been made to standardize e-government assimilation stages and to measure the level of maturity that an e-government project has achieved [4]. This has resulted in the development of the several e-government maturity models [5]. While existing e-government maturity models have been adopted to develop strategic plans to deploy e-government projects, studies [6,7] show that an increasing number of e-government projects in developing countries are failing to align with the patterns of e-government 
maturity models, resulting in poor sustainability of these e-government services. The word sustainability has been loosely used to define the efficiency that a government could achieve in terms of cost, time, and effort to implement e-government services, while being able to accommodate the interests of various stakeholders (i.e., the government and citizens). Further assessment of e-government maturity models has brought forward several limitations to our knowledge, namely a lack of adoption (emphasis on technology), a linear pattern of stages, a lack of detailed processes, and a lack of state-of-the-art technology. Such limitations obstruct the design of sustainable e-government services, making it imperative to design alternative maturity models. We considered two research questions for the purpose of this study.

- Why are the existing e-government maturity models failing to align with the e-government projects' assimilation processes in developing countries?

- How could the limitations of these models be addressed to achieve sustainable e-government services?

To answer the above research questions, we synthesized the existing e-government maturity models. We analyzed the models based on the number of stages, and the nature of maturity they proposed at each stage. This provided a better understanding of why these models failed to provide strategic plans to execute sustainable e-government services. Based on the findings acquired from the analyses of the exiting e-government maturity models, we proposed and validated a new e-government maturity model that would support governments in developing countries in achieving sustainable e-government services. Unlike the existing maturity models, the proposed model distinguishes itself by introducing adoption stages along with the implementation stages. We set certain parameters for sustainable e-government services, such as cost efficiency, time efficiency, effort required to deliver services, and adoption rate of the offered services. The proposed maturity model was evaluated by employing case-study and survey methods in a real e-government project. Our results showed that this approach brought efficiency to government processes in terms of cost, time, and effort required to implement e-government services, while the survey findings showed that activities defined in the adoption stages (i.e., range of delivery channels, awareness and trust, and quality of services) encouraged more users to use e-government services.

\section{E-Government Maturity Model Background}

Along with technological advancements, many variants of maturity models were proposed by various researchers. Almost all these models agreed that development of the electronic government occurred in a linear and progressive manner, where the government achieved its maturity at different stages. The existing e-government maturity models comprise two to nine stages. Among the existing models, the most discussed and cited ones have a maximum of six stages. Reddick [2] proposed a two-stage maturity model which defines the maturity stages as a catalogue, where governments arrange information in a catalogue accessible by citizens and businesses, and a transaction, where governments offer full-fledged e-government services. Howard [8] developed a three-stage model with stages named publish, interaction, and transaction, where governments initially publish information online, then interact with stakeholders online, and finally, allow users to have online transactions. Layne \& Lee [1], Andersen \& Henriksen [4], Gartner [9], Chandler \& Emanuel [10], and West [11] adopted much more balanced approaches to government maturity models, where they emphasized that e-governments could reach maturity in four stages. Among these models, Gartner's maturity model was slightly different from the others. It said that e-governments could achieve transactions in the third stage, whereas others put the transaction phase in the second stage.

Some authors [12-15] developed five-stage models, particularly for developing countries where e-government assimilation took place at a slow pace. Some comparatively old models, namely the Asia-Pacific [16] and Deloitte [17] models, further broke down the assimilation process, and proposed six-stage maturity models. These models provided a slower assimilation process where the government started from a very basic point, such as through the use of an email system, and made small-incremented progress toward maturity. While assessing the existing e-government models, we found that they had 
very few distinct differences; in fact, most of the models were inherited from previous models, and loosely modified within the contexts of various countries. Howard [8] and the World Bank [18] developed almost identical maturity models, which shared a similar number of stages with metaphors used for each stages also being the same. These models argued that e-government implementation is done in three stages, where governments initiated an e-government firstly by publishing (website), followed by two-way communication, before finally arriving at the transaction stage. The maturity level of e-governments was purely portrayed as an e-commerce, where the government's goal was to transact with stakeholders electronically. Similarly, Gartner [9], and Chandler \& Emanuel [10] developed four-stage maturity models which also had very similar stages. The two differences were the metaphors used for the first and last stage. Gartner [9] presented the transformation of government services as maturity of the electronic government, whereas integration was proposed at the maturity stage of the e-government in Chandler \& Emanuel's [10] model. Siau \& Long [15], and Shahkooh et al. [14] had stages identical to those of the Gartner [9] maturity model. The only difference between the Gartner [9] model and the other models was the number of stages. The other models had five stages, and proposed e-democracy or digital democracy as the maturity level of the electronic government. These models defined electronic government in a much wider perspective than previous models by including a stage where citizens got involved in government activities.

Despite their uses, e-government maturity models acquired criticism from several researchers: Coursey \& Norris [19], Debri \& Bannister [6], and Zahran et al. [7]. They observed several limitations in existing maturity models. Coursey \& Norris [19] analyzed maturity models developed by the Gartner Group, by Layne and Lee, and by Wescott [16], and found that the models were speculative and lacked the statistical data to support the usability of the maturity models. Furthermore, they noticed that patterns of e-government development at the local level were not supported by these models. Karokola \& Yngstrom [20] described the models as technology-centric and as including many buzzwords. According to them, the models focused on the naming of stages, with security requirements being disregarded at each of those stages. Similarly, Lee [21] studied a dozen e-government maturity models, including his own model developed in 2001, and found that the maturity models were somehow similar other than the metaphors used in each one. He further indicated the need to redesign maturity models to include modern technology available at the time of the e-government's implementation. Debri \& Bannister [6] found that e-government maturity models were descriptive and predictive, and lacked practical solutions to achieve maturity of stages. They said that maturity models presented a narrow definition of e-government, which saw e-governments as tools to provide web-based e-government services. Zaharan et al. [7] found that existing maturity models were too simplified and were developed based on assumptions. They said there were no facts available to assess how successfully the stages in the models addressed e-government assimilation. They found that the models were supply-oriented and ignored the side of adoption. Therefore, considering none of the models as universal, all the above authors developed their own versions of maturity models.

\section{Limitations of the Existing E-Government Maturity Models}

All the mentioned existing works are important and have already contributed to e-government implementation. However, several limitations were identified by various researchers which are given below.

Limitation 1: E-government assimilation occurred in a linear pattern

Almost all electronic government maturity models agreed that the assimilation of electronic governments occurred in a linear manner where the e-government project progressed from simple to complex technology [22]. The models introduced by Layne \& Lee [1], Gartner [9], the United Nations (UN) [23], Reddick [2], and West [11] argued that an additional stage needed to be completed before starting the following stage. This may have been partially true; however, modern technology could enable governments to initiate two or more stages simultaneously (e.g., governments could introduce e-governments along with their integration into the government department [24]). This depends on 
the government's decision whether or not it has enough resources to start two stages (e.g., introduction and integration) simultaneously.

Limitation 2: Transaction occurred before integration

All existing e-government maturity models agreed that the transaction stage was to be implemented before the integration stage of e-government maturity (see Table 1). However, transactions were not completely achieved without integrating e-government services and systems at different levels. The process of government service delivery needed to go through various authentication and verification processes, and often required an involvement of two or more government departments working together to complete service requests from a stakeholder. In such a situation, if those government departments had disparate systems, online services were not delivered effectively and efficiently. Therefore, it is imperative to integrate government departments to seamlessly deliver online government services. A study conducted by the UN in 2014 showed how e-government assimilation stages were achieved.

Table 1. Extent of electronic service (e-service) delivery stages in various countries (the United Nations [25]).

\begin{tabular}{ccccc}
\hline Countries & $\begin{array}{c}\text { Stage 1 Emerging } \\
\text { Presence }\end{array}$ & $\begin{array}{c}\text { Stage 2 Enhanced } \\
\text { Presence }\end{array}$ & $\begin{array}{c}\text { Stage 3 Transactional } \\
\text { Presence }\end{array}$ & $\begin{array}{c}\text { Stage } \mathbf{4} \text { Networked } \\
\text { Presence }\end{array}$ \\
\hline Japan & 97 & Service's maturity level in percentages (\%) & 79 & 88 \\
Netherlands & 100 & 73 & 70 & 58 \\
Estonia & 100 & 75 & 56 & 44 \\
Costa Rica & 94 & 66 & 37 & 50 \\
Jordan & 91 & 55 & 21 & 24 \\
South Africa & 75 & 41 & 12 & 35 \\
Indonesia & 69 & 43 & 9 & 15 \\
Senegal & 78 & 34 & 5 & 9 \\
Kyrgyzstan & 81 & 32 & 2 & 9 \\
Zambia & 47 & 27 & 0 & \\
\hline
\end{tabular}

The above table shows that almost all the countries, regardless of their development status, achieved networking/integration of government departments before the transactional stage. A study conducted by Tripathi \& Gupta [26] on the maturity level of the Indian e-government also provided similar findings to those of the UN [25] report. The government of India adopted a four-stage maturity model to implement its e-government. Tripathi \& Gupta [26] found that, at the time, 58 percent of the e-government services had achieved integration, while only 28 percent of the e-government services had achieved the transaction stage. This clearly indicated inconsistency between the maturity models and the e-government's development. Therefore, maturity models should be designed in such a way that the integration stage is completed before the transaction stage.

Limitation 3: Lack of state-of-the-art technology

Supriyanto \& Mustofa [27] said that existing maturity models failed to include advanced and modern technology in e-governments' developmental stages. Technology has rapidly changed in the last decade. The use of social media has dramatically increased, more people have access to the internet, the global community has become closer, and information has become more open. Many technologies are currently outdated, for example, dial-up internet, static web pages, etc. are rarely used. Therefore, maturity models should be developed at regular time intervals to include technology of that particular time [28]. Maturity models should be developed in such a way that they can address current problems, and consider the use of modern technology.

Limitation 4: Lack of a detailed process

Some existing electronic government maturity models were developed to rank the maturity levels of electronic governments [14]. These models did not provide a strategic solution to achieving stages 
of an electronic government [29]. These models do not say anything about the processes and activities needed to follow progress from one level to another. The existing models are descriptive and predictive with no factual or technical plan to initiate or complete stages. The stage models proposed by two different organizations, the UN [23] and the Asia-Pacific [16], claimed that the models would work best in developing countries. Like other previous models, the UN [23] proposed an emerging presence where the government established their static website as the initial stage of e-government assimilation, but did not provide any processes that defined how governments should initiate their web presence.

\section{Limitation 5: Lack of adoption perspectives}

Some existing electronic government maturity models rank the maturity of electronic governments based on the technology in use [30]. Almost all maturity models agreed that governments using sophisticated and advanced technology achieved greater levels of electronic government maturity. However, Debri \& Bannister [6] argued that sophistication of technology may not correctly predict the maturity level of electronic governments. The success of e-governments should not be measured merely based on sophistication of the technology used by the government, but instead, should also consider whether or not the services offered are being used by the stakeholder [6]. The ratio of stakeholders using the online services to the services offered also needs to be assessed to evaluate the success of an e-government. However, these facts seem to be ignored by electronic government maturity models. No e-government model has included the user as someone who plays a crucial role in the successful implementation of an e-government [7].

These limitations can be considered as the determinants of sustainable e-government services, as they impact the whole e-government project. Considering the abovementioned limitations, we concluded that e-government maturity models must address these limitations in order to support governments in the designing of sustainable e-government services.

\section{E-Government Maturity Model for Sustainable E-Government Services}

E-government maturity models play a key role in designing sustainable e-government services by assessing the context of e-government project implementation, and by providing appropriate strategic plans to execute the projects [31]. A well-designed and well-assessed plan would provide a better understanding of the strengths and limitations of governments, allowing the selection of the best possible approach to e-government project assimilation for its sustainability [32]. Sustainable e-government services should be capable of supporting governments to achieve their goals, and provide operational simplicity while proving valuable for investments, in terms of quality of services, wider acceptance and adoption of the offered services, cost of e-government implementation, and operational efficiency. Moreover, the increased lifespan of e-government services, and the flexibility to bring in changes when required by technology are also some of the key characteristics of sustainable e-governments. More specifically, we define a sustainable e-government service as below.

A sustainable e-government service is the ability of citizen-centric trustworthy e-government services that adopt state-of-the-art technology to deliver a cost-saving, resilient, and effective service, and to support active participation and satisfaction from all levels of user.

While defining the sustainability of e-government services, we considered two different dimensions-implementation and adoption. The implementation dimension deals with the technology, budget, and human resources required to implement e-governments, whereas the adoption dimension considers the design and approach of e-government service delivery for wider user participation and adoption. We incorporated these dimensions into our proposed model to support governments in developing countries in the design of sustainable e-government services. 


\section{Determinants of Sustainable E-Government Services}

Based on the limitations of existing e-government maturity models, we proposed a number of determinants that must be incorporated into a maturity model to support governments in delivering sustainable e-government services. Figure 1 shows how inclusion of the defined determinants contributes in designing a viable e-government maturity model that supports governments in achieving sustainability.

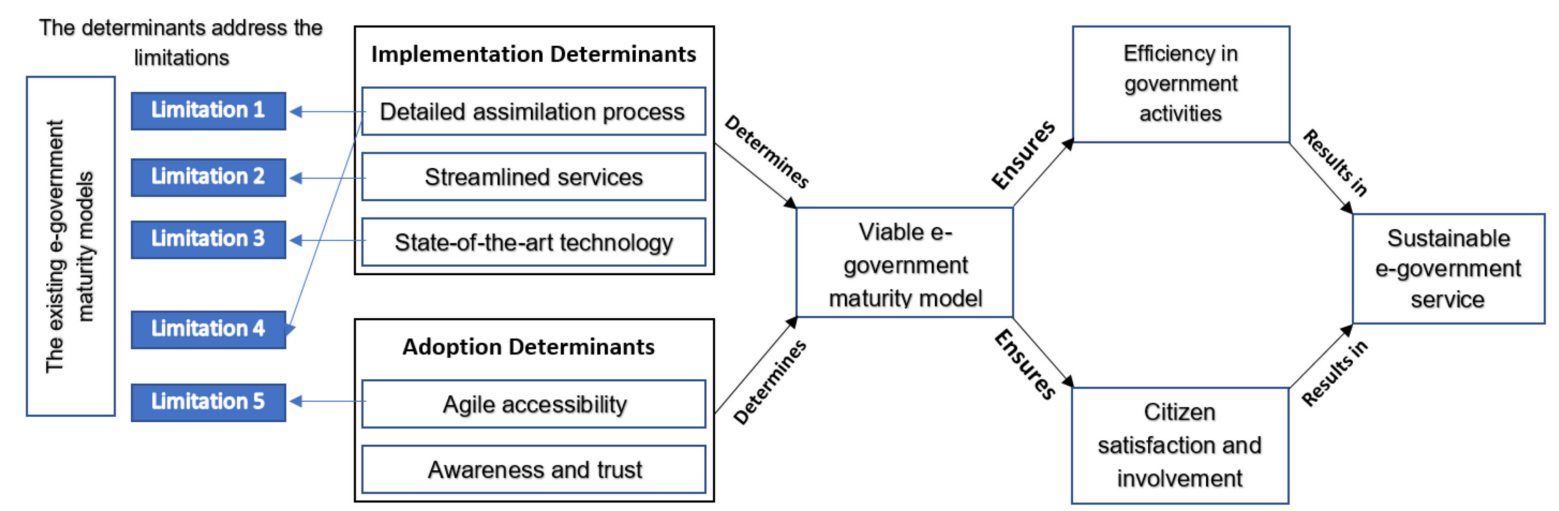

Figure 1. Determinants of the electronic government (e-government) maturity model for a sustainable e-government.

The determinants were defined from both implementation and adoption perspectives. Each determinant attempted to address one or more limitations of supporting governments in achieving efficiency along with active citizen involvement.

\subsection{Implementation Determinants}

The implementation determinants of e-government maturity models made sure they delivered the best possible approach for e-government implementation by providing clearly-defined stages, and the activities required to achieve those stages. The implementation determinants focused mainly on how governments could achieve streamlined e-government services in developing countries. The following implementation determinants were proposed for a viable e-government maturity model that results in sustainable e-government services.

Determinant 1: A detailed assimilation process is desirable for a viable e-government maturity model.

E-government maturity models should be able to provide a detailed outline of processes required to achieve the stages of e-government assimilation. A lack of detailed processes often brings confusion when initiating a stage, as there is no explanation of how each stage will be accomplished [29]. Existing maturity models fail to provide the activities required to achieve certain stages of the e-government assimilation [14]. Therefore, the inclusion of detailed assimilation activities would contribute toward a viable e-government maturity model.

Determinant 2: E-government maturity models should support governments in designing streamlined services.

A sustainable e-government requires government services to be more citizen-centric and streamlined [33]. Disparate e-government systems and individual databases discourage users from adopting the offered services as they result in incomplete adoption and may require secondary action, such as visiting government offices in order to complete service requests [24]. Furthermore, individual and disparate electronic government systems are becoming financially less sustainable for developing countries, as their maintenance demands excessive budgets, and replicates government processes [34]. Unless these systems become centralized or connected, government officials must process service requests manually, resulting in inefficiency and lower productivity [35]. Therefore, a sustainable maturity model should be able to support the government in delivering streamlined services through the integration of a government system. 
Determinant 3: E-government maturity model should emphasize using state-of-the-art technology.

Technological models and frameworks need to be frequently updated to accommodate the most recent changes in technology [27]. To endure and remain competitive, technological projects (i.e., e-governments) need to adopt state-of-the-art technology [31]. Most maturity models were developed quite a few years ago, and therefore lack the strategy to make e-government projects more efficient through the adoption of recent technology [21]. We emphasize the use of cloud-computing platforms for e-government services. While traditional technologies are becoming financially less affordable to maintain and operate, and also more complex, we stress that governments should adopt more sophisticated and recent technology when it comes to extending e-government services in developing countries.

\subsection{Adoption Determinants}

Adoption of electronic governments is as equally important as the electronic government itself in order to become successful [19]. Adoption of e-governments refers to the active participation of citizens in e-government activities. Therefore, e-government maturity models should also provide a strategy to gain maturity from an adoption perspective. The adoption of e-government services and user involvement depends on a number of determinants, such as accessibility of the services, trust, awareness, and ease of use. Therefore, these determinants need to be appropriately addressed when designing e-government maturity models.

Determinant 4: E-government maturity models should support the government in identifying agile accessibility to the service.

Accessibility of e-government services is strongly related to its success. Agile accessibility ensures that the offered services can be used by the widest possible range of people, in terms of their abilities. Specifically, while developing countries are facing a huge challenge from a digital divide among citizens, governments must make sure all citizens can equally enjoy e-government services. Riggins and Dewan [36] found that particular groups of people were disadvantaged in their uptake of information communication technology (ICT) in developing countries. These include people on low incomes, people with few educational qualifications or a low literacy level, the unemployed, elderly people, people in isolated or rural areas, people with disabilities, women, and girls (Cullen [37]). Lack of access to the computers and internet further restrain them from adopting e-government services. Therefore, sustainable e-government maturity models should support governments in determining various channels of e-government service delivery.

Determinant 5: E-government maturity models should be able to support governments in developing awareness and trust among citizens.

The proposed maturity model strongly emphasized building awareness and trust among citizens for sustainable e-government services. Lack of awareness about the benefits of e-governments remains a critical factor in user adoption in developing countries. Many factors, such as education, race, and culture have contributed toward a low level of user awareness [29]. It also came to our attention that some clusters of society (i.e., women, people considered of a lower caste, and people under the poverty line) had considerably lower awareness about e-governments. Meanwhile, Hollenstein [28] highlighted that building trust among citizens toward e-government services was most essential for e-government success. Users need to be assured of the legitimacy and authenticity of e-government services, and that personal details processed online are secured with confidentiality remaining intact. Therefore, to increase user participation and to make e-government services accessible to the isolated clusters of society, governments should work on building awareness and capacity.

\section{An E-Government Maturity Model for Sustainable E-Government Services}

The proposed model was based on determinants mentioned in the previous section in order to deliver sustainable e-government services in developing countries. The first implementation 
determinant, a detailed assimilation process, was addressed by providing detailed activities at each stage, and by defining how these activities will contribute toward achieving individual stage maturity. The subsequent determinants, streamlined services and the use of state-of-the-art technology, were addressed by placing the integration stage before the transaction stage, as seen in Figure 2 . The integration stage defined how state-of-the-art technology could be used to integrate isolated e-government systems to deliver streamlined services. Furthermore, the adoption determinants (agile accessibility, trust, and awareness) were accommodated in the adoption stages. The adoption stages of the proposed model defined various channels of e-government service delivery that supported agile accessibility. Moreover, the activities under the adoption stages provided detailed explanations of how governments could increase trust and awareness to acquire wider participation from users. One of the key differences between the proposed model and existing models was the inclusion of adoption stages to acquire participation from stakeholders. The figure below describes the importance of accommodating adoption stages in maturity models, and provides a roadmap for governments to achieve wider acceptance from stakeholders.

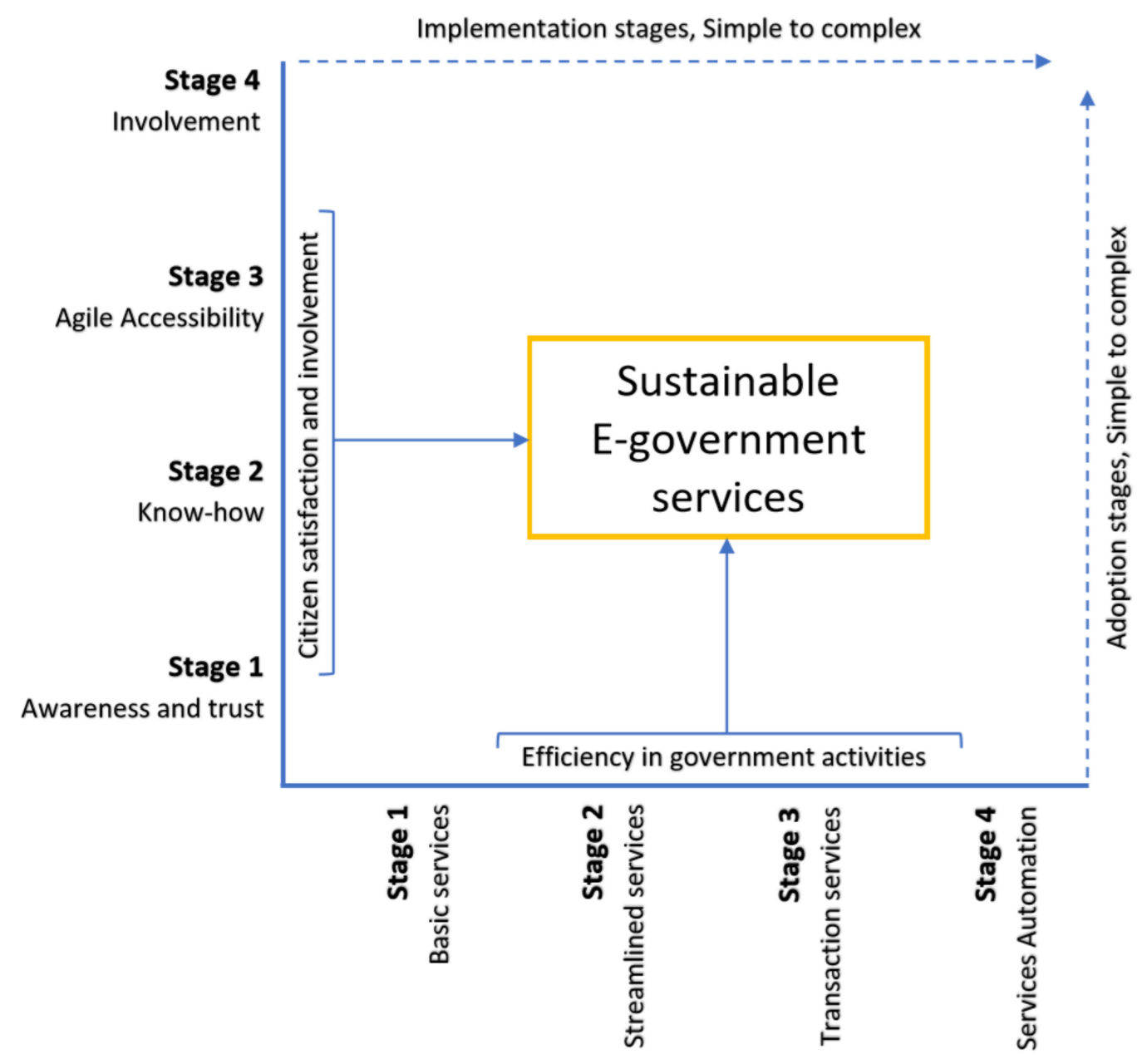

Figure 2. E-government maturity model for sustainable e-government services.

\subsection{Implementation Perspectives}

This model considered four implementation stages and emphasized the integration of e-government systems before invoking the transaction stage. The stages and the tasks under those stages were identified and are discussed below to provide a detailed plan for e-government implementation. 


\subsubsection{Stage 1: Basic Services}

The initial stage proposed by the maturity model was to introduce basic e-government services. Unlike existing e-government maturity models, the proposed model emphasized using social media and establishing a web presence to communicate with stakeholders. Use of social media (i.e., Facebook, Twitter, YouTube, LinkedIn, etc.) is great to reach out to masses of people. This stage explained how governments could gain trust from citizens by addressing their queries through a web presence. Furthermore, this stage supported governments in developing awareness among stakeholders in relation to e-government services. The activities needed to be performed to achieve this stage were identified by the maturity model and are listed below.

Activity 1: Computerization of the government departments

The first step of the initial stage of e-government implementation was to computerize government departments. Governments are to provide appropriate training to their employees in order to operate computers and basic computer applications used in government offices. Along with computers, other hardware devices, such as printers, scanners, and storage devices are also to be installed. Government departments and offices are also to connect to the internet.

Activity 2: Cataloguing the information

Once governments have computerized their departments, they are to start cataloguing data they hold in paper format. Governments are to then transfer hardcopies of the data held by government offices into a digital format.

Activity 3: Website development \& social media presence

Along with the cataloguing of information, governments are to start developing websites and establishing social media presence. Social media, such as Facebook, Twitter, YouTube, and LinkedIn are suggested as effective approaches to reaching an increased number of stakeholders.

Activity 4: Building awareness

Along with all the above activities, governments are to emphasize a program for the development of awareness. Governments are to have the responsibility of developing the skill and expertise of government employees, and of educating stakeholders about e-government initiatives.

\subsubsection{Stage 2: Streamlined Services}

The maturity model emphasized streamlining e-government services for their sustainability. Streamlined services were defined as complete and integrated services, where stakeholders could acquire specific government services without having to visit relevant government offices. This would require the integration of e-government systems into various government departments. Integration is to be done along with the establishment of the electronic government infrastructure in order to save government resources, and to avoid the risk of data replication, as shown in Figure 3. Without vertical integration, governments could end up with several individual fragmented electronic government applications and data repositories. Vertical integration would interconnect government departments that shared similar interests in order to avoid data replication, and to enhance service delivery. Furthermore, streamlined government services would eliminate the manual data processing layers from various government departments. This has high implications in the context of developing countries, where citizens have poor access to ICT tools, integrated databases, and authentication systems which would allow local government officials to better serve them. Therefore, we emphasized the integration of the disparate and individual databases and applications before moving to the transaction stage. 


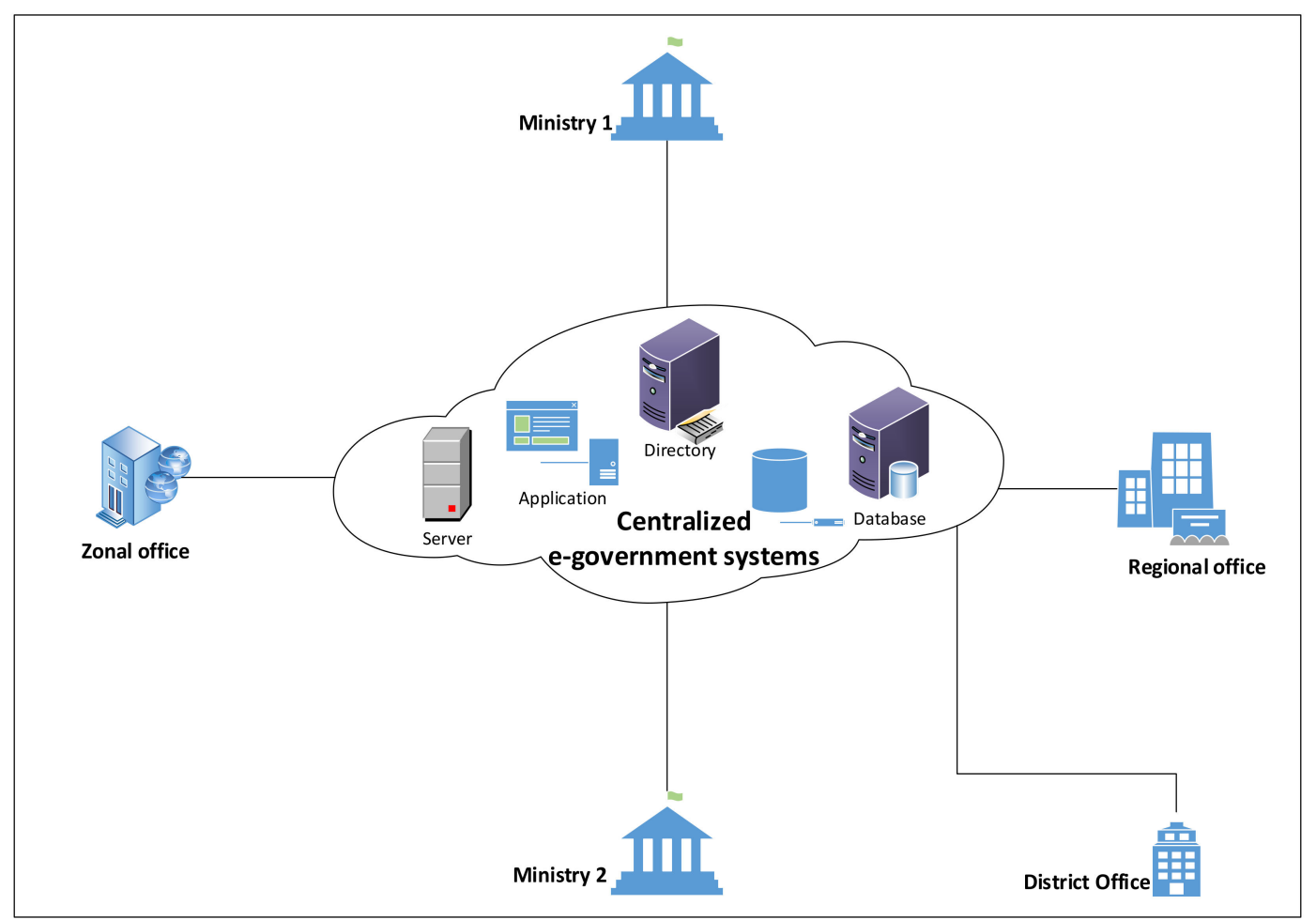

Figure 3. Integration of an e-government system for streamlined e-government services.

The tasks required to achieve streamlined e-government services were identified by the maturity model and are listed below.

Activity 1: Enhance networking and connectivity

The primary task for the government to establish interconnection between government departments would be to build effective networking for reliable connectivity. Governments are to establish wired (fiber-optic or cable) and wireless connectivity to achieve this interconnection.

Activity 2: Establish an interoperability frmework

An interoperability framework is to be developed allowing systems in various government departments to communicate effectively.

Activity 3: Identify integration platforms

It would be challenging for developing countries to achieve interconnectivity as it would require an excellent and reliable networking infrastructure. Therefore, developing countries could consider cloud-based integration as a potential solution of government integration at various levels without the need of a physical networking infrastructure.

\subsubsection{Stage 3: Transaction Services}

This maturity model proposed transaction services at the third stage. All existing e-government maturity models considered transactional services at the second stage. In contrast, we placed this stage after the integration stage. It can be argued that, without achieving integration, transactional services cannot be delivered efficiently. The integration of government departments and e-government services would allow various departments to communicate in real time, avoiding any delays in the processing of payments. At this stage, governments would establish a payment gateway, allowing stakeholders to 
acquire services online, and would also establish an effective communication mechanism, allowing governments to become more interactive. The tasks required to achieve the transactional stage were identified and are listed below.

Activity 1: Government legislations for electronic data processing

Governments are to introduce legislations and regulations in relation to electronic data processing and the validity of electronic transactions in order to make electronic transactions legitimate and to build trust among stakeholders.

Activity 2: Establish a verification mechanism

To provide real-time e-government services, governments are to have mechanisms in place verifying data and identities of users. Verification could be fully automated, or manually automated in the case of complex information. User identity documents (IDs), voter IDs, driving licenses, or passports could be used for identity verification.

Activity 3: Establish a payment gateway

This would be the most important activity required by governments to provide fully functional e-government services. Governments in developing countries could establish private business partnerships for payment processing, and could integrate online banking or mobile banking for government services so that users could make financial transactions.

Activity 4: Roll out online services

Once governments have established online documents, transaction verification services, and payment gateways, they are to offer the services online.

\subsubsection{Stage 4: Automated Services (One-Stop Shops and E-Democracy)}

Automation is the fully mature state of e-governments where users are proactively involved in government activities. In this state, government services are transformed from a push to a pull (demand-driven) format. E-government services also become smarter, synchronize with user accounts, and provide automated services, such as text reminders regarding unpaid bills, license and ID renewals, etc. The tasks required to achieve this stage were identified and are listed below.

Activity 1: High-level integration

Governments are to establish high-level integration where departments are vertically (same department at various levels) and horizontally (various departments at various levels) integrated. All government departments are to share data, avoiding any middle layers, making the system smarter.

Activity 2: One-stop shop

Governments are to develop single-window government portals, allowing stakeholders to access all available government services from one place. Governments are to provide unique IDs to registered users, which are to be used to access all e-government services.

Activity 3: Synchronization

Governments are to synchronize user data with government systems to provide tailored services to stakeholders. User accounts are to be synchronized with calendars to provide important dates that users are to act on (e.g., permit renewals, tax payments, social security payments, etc.). 


\subsection{Adoption Perspectives}

The proposed model identified four adoption stages where stakeholders were to have gradually experienced electronic government services, and been proactively involved in e-government activities. The adoption side was more focused on human and organizational issues. The adoption stages emphasized the creation of value for stakeholders at each stage of e-government implementation. The proposed maturity model integrated the adoption stages within the implementation stages, so as to better guide governments toward developing combined strategies to achieve citizen satisfaction, along with efficiency in the implementation of e-government services. The adoption stages, and the tasks which fell under them are discussed below.

Stage 1: Awareness and trust

This stage is to go along with the introduction stage of e-government implementation. Stakeholders are to be prepared for changes that take place in the delivery of government services, and channels of interaction. Along with awareness and training, governments are to put their efforts into making stakeholders ready for the change.

Stage 2: Know-how

Know-how refers to the practical knowledge of how to adopt the offered e-government services. As governments start providing streamlined services, the knowledge of stakeholders is to be enhanced in order for them to get involved in e-government activities. Stakeholders are to be provided with appropriate training through workshops, seminars, television programs, and other means of communication to enhance their knowledge in relation to the benefits of electronic government services, and how these services are to be achieved.

Stage 3: Agile accessibility

This stage is to go along with the integration and transaction stages of implementation. Various factors, such as access to technology, personal circumstances, social influence, availability of service, reliability of service, security, and trust will affect users' decisions to adopt or discard the online services. Among these factors, access to technology is the most critical in relation to developing countries. Therefore, the proposed model emphasized the establishment of agile accessibility to e-government services. Agile accessibility to e-government services could be achieved by developing various channels to deliver services (e.g., telecenters, kiosks, private business partnerships, and rural municipalities). Especially in the context of developing countries, where the digital divide among people is apparent, agile accessibility will make sure that stakeholders with various levels of ability will have an equal chance to acquire e-government services. Figure 4 shows how various channels of delivery can ensure agile accessibility to e-government services.

Stage 4: Involve

The maturity stage of user adoption of electronic governments was described by the involvement of stakeholders in government decision-making. At this stage, stakeholders would have the chance to have their say in government activities, and could actively participate in government legislation. Governments could acquire the view of stakeholders from various channels, such as online consultations, live chats, public polls, etc. 


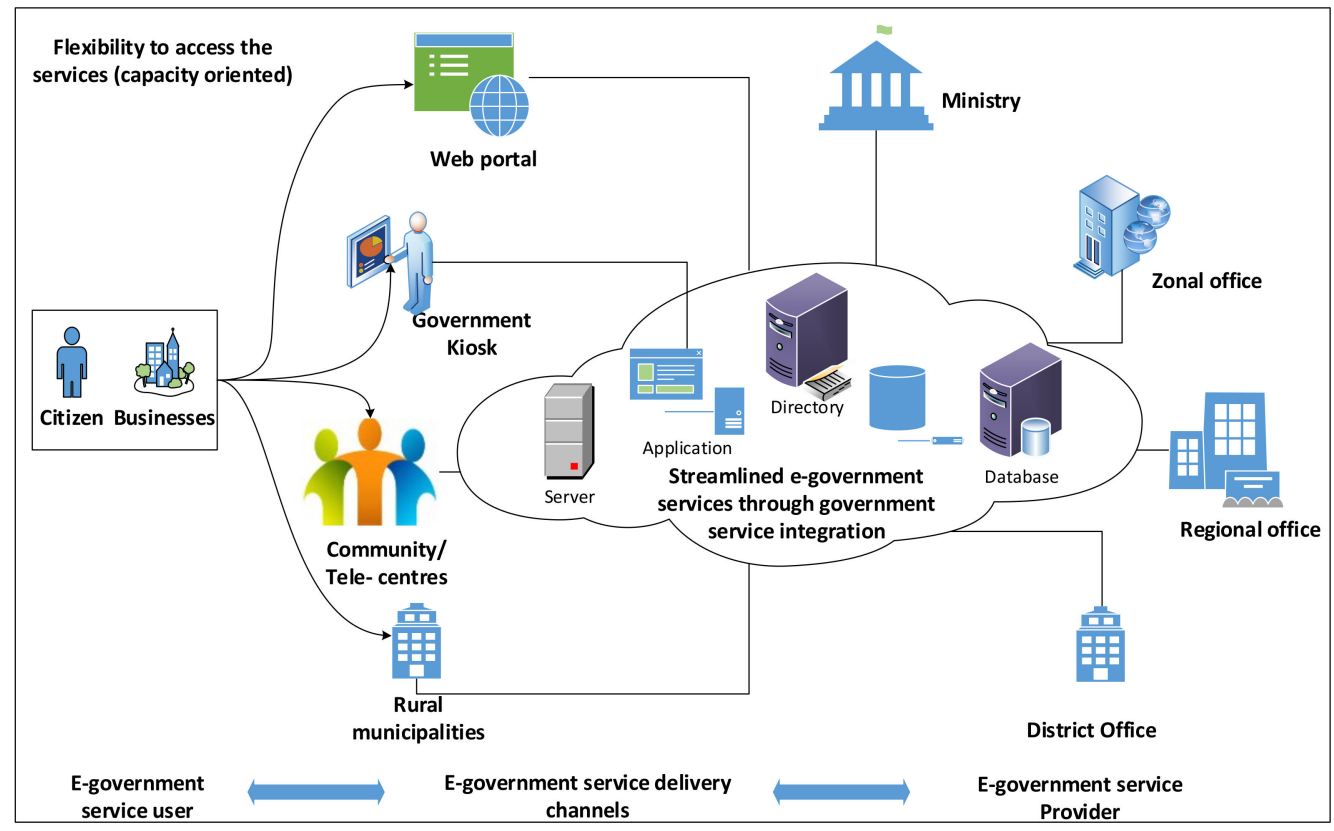

Figure 4. Deliver of e-government services via various channels.

\section{Evaluation}

We considered empirical investigations to evaluate the applicability of the proposed maturity model. In particular, as shown in Figure 5, both the case-study and survey methods were used for this purpose. We defined evaluation parameters from the perspective of a sustainable e-government service, that is, cost, time, effort, and the adoption rate of offered services. The findings of the case study and survey were assessed against the set parameters to evaluate whether or not the proposed model was able to meet them. The rationale behind using two different methods of evaluation was the nature of the parameters required. The cost, time, and effort to implement e-government services was evaluated by employing a case-study, as it required actual implementation of the model in a real project. Meanwhile, customer satisfaction and adoption of e-government services was evaluated by the survey method.

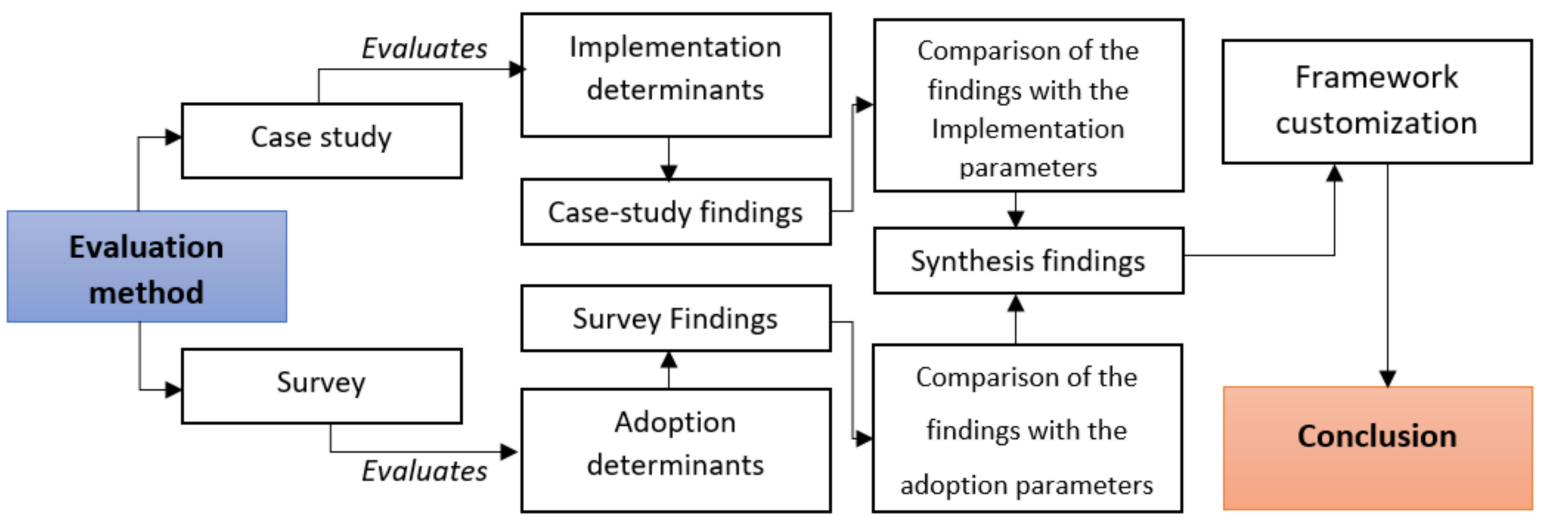

Figure 5. Evaluation approach.

\subsection{Case Study}

We adopted a case-study approach to validating the implementation determinants of a viable e-government maturity model. A case-study method is considered the best approach when data acquired from research needs be presented in a descriptive and explanatory way (Gillham [38]). As we 
aimed to provide rationales for using the proposed model for sustainable e-government services, we adopted a case-study method, where we observed and recorded the opinions of participants while implementing the model in a real scenario.

\subsubsection{Study Construct}

The objective of the case study was to evaluate the defined determinants on the basis of their impact on sustainable e-government services. We argued that the inclusion of the determinants in the e-government maturity model provided governments an efficient approach to implementing e-government services. Therefore, we hypothesized the determinants as follows:

Hypothesis 1. The detailed assimilation process provided by the proposed maturity model would positively support governments in designing sustainable e-government services.

Hypothesis 2. The proposed maturity model would support governments in delivering streamlined services that result in a sustainable e-government.

\subsubsection{Study Context and Rationales}

The context of this study was the citizenship verification service in the government department regulating passports in Nepal. All Nepali citizens beyond the age of 16 are issued with a paper-based identity card called a citizenship certificate, which is proof of their nationality and is used to get various government services. These citizenship cards are issued by the District Administration Office and the Area Administration Office upon recommendation by local bodies, pursuant to the Citizenship Act, 2063 Bikram sambat (B.S.). The details of citizenship are held in their respective districts, and have to be manually fetched. Alternatively, users have to verify their citizenship cards from the districts they have been issued each time they require certain services (e.g., to get Nepali passport). This has become a critical issue for citizens residing far from home. These citizens must travel to their respective districts just to get verification, which is then brought to the ministry of foreign affairs prior to getting a passport. This process takes considerable time and cost, as transportation in various areas of Nepal is still a big issue. Therefore, we decided to contact the department for our case study, and to integrate a digital database of citizenship in various departments, so as to streamline the citizen verification process, saving both the government and the citizens time and effort. Nepal's government also realized the need for a consolidated and centralized database of citizens, and took initiative to replace the old paper-based citizenship certificate with a new biometric card in 2010, and established the national ID management center in 2011. The government aimed to provide prompt and quality service to citizens at minimum cost, to maintain good governance, and to control crime in the society by introducing the national ID card. However, the project is not yet completed. As the department was seeking to streamline its data to achieve efficiency, the rationale for selecting them was to assess the proposed model for its applicability in achieving sustainable e-government services, involving the assessment of cost-saving, time-saving, and efficiency of government services.

\subsubsection{Study Plan and Team}

Firstly, we identified the maturity model adopted by the department to assimilate e-government projects. We had a formal discussion with the participants, and assessed the government plan available in its portal, and we found that the Nepali government had adopted a four-stage model, like Layne \& Lee, for the assimilation of their e-government. Secondly, we identified the stage of e-government service maturity in the department. We assessed several government portals and the services they offered to determine the maturity level of e-government services. From the assessment, we found that the government achieved the first stage of basic services, according to the proposed maturity model. As the government had already achieved the first stage, we decided to initiate activities required to achieve 
the second stage, as defined by the maturity model. Once we gathered all the required information, we assembled a team to conduct the case study. As we had conducted a similar case study in a different department, we first approached government officials from that department to assist officials in the department regulating passports. After a few attempts, we convinced the officials to pilot the proposed model. However, they did not agree to test the model with their live system. We all agreed to replicate the e-government services, and reformed them as described by the proposed maturity model. We formed a team of government officials, e-government Information technology (IT) staff, and a local entrepreneur who provided us with technological support. The team members worked together to implement the maturity model, and observed the outcomes as the activities took place. The team members were allocated their roles in the case study. Government employees supported us by providing appropriate information required to assess the current e-government status, such as the system used, the model used, and other government data required while conducting the case study. The government IT staff and the local ICT entrepreneur performed technical tasks, such as system integration, customization, networking, etc.

\subsubsection{Implementation Process}

Once the study plan was formed and the required information was gathered, we started the activities defined by the proposed model. As we were implementing the proposed model in an existing e-government project, we first needed to assess the readiness of the country when it came to an e-government. E-government readiness refers to the organizational and technological capacity of a government to execute e-government projects. Organizational readiness for the adoption of an e-government is related to the legal framework for e-government activities, the availability of human resources, and the availability of the budget. Technological readiness refers to the available technology to implement e-government projects, the capacity of the people to adopt the offered e-services, and reliable connectivity. The assessment process involved discussions with the government officials, assessment of the data from internet service providers in the country, and analysis of previous study findings from various organizations. From the assessment, we found that the Nepali government had introduced many laws over the course of the last decade, in relation to e-governments, and information and communication technology. Appropriate measures had already been taken to reform the process of service delivery in the government. Organization and computerization of most of the government offices had already been done. Twenty-seven government ministries had digitalized their day-to-day work. Almost all district headquarters were connected to the internet, although connectivity remained an issue. From the findings, the participants agreed that the government of Nepal had achieved the basic level of e-government readiness, and was continuously improving its capacity toward advancement. The participants also agreed that a lack of access to technology, education, and awareness among citizens was an issue when it came to adoption. Therefore, the proposed maturity model became more relevant in the given context, as the model accommodated the adoption stages, which defined how a user could adopt the offered services. As the findings of the assessment suggested that the Nepali government had achieved the first stage of the implementation of e-government services, we decided to initiate the second stage of the proposed maturity model. Meanwhile, we found that the e-government services offered by the government had failed to attract users. Therefore, we decided that the adoption stages were to be started immediately. The case study was limited to the implementation of the second stage of the maturity model, as it was not practically viable to implement all stages. Furthermore, since we defined sustainability as efficiency in the delivery of government services, and the adoption of those services, we could mostly achieve this in stage two. The other stages can be achieved as the government moves toward more advanced technology, and gradually makes progress. These stages can be further evaluated in future research.

\section{Implementation Stage 2: Streamlined Services}

As decided by the participants, we started with the second stage of the maturity model. Unlike other maturity models (transaction in the second stage), the second stage of the proposed model 
was the streamlining of services, which could be achieved through the integration of government departments. The integration of government systems in various government departments is a complex task. In relation to the Nepali government, the servers of various government departments were co-located. However, integration still needed to be done. Furthermore, various layers of individual government departments had not even been integrated, creating data isolation problems. The same problem existed in relation to the citizenship data. The data was individually held in various offices, and required manual communication to various departments. This took time, and resulted in poor efficiency of the service, and poor customer satisfaction. As defined by the proposed model, we performed various activities to achieve streamlined services.

Activity 1: Enhance networking and connectivity

The first task towards achieving streamlined services was to enhance networking and connectivity between government departments and offices located in various geographical locations. The government departments had already recognized the need for better internet connectivity and networking between them for seamless communication. As an effort to enhance internet connectivity, Nepal successfully implemented a fiber-optic network with China in 2018. The government believed that the fiber-optic connection between Nepal and China would increase the reliability and speed of the internet connection, and minimize the dependency on internet networks connected solely via India. In relation to internet access between government offices located in various districts, Nepal had successfully connected 55 of the 75 districts with the optical fiber network in 2017. Similarly, remote government offices had been connected to the central office through Code Division Multiple Access (CDMA) and third generation $(3 G)$ networks. However, these efforts were not enough to achieve sustainable e-government services. For this to be the case, the government should speed up the process, and prioritize the task of networking and connectivity.

Activity 2: Establish an interoperability framework

Interoperability is the one of the issues faced in developing countries. As various government departments develop their own system to digitalize their work, the integration of these systems becomes challenging. Therefore, we assessed the e-government initiative of Nepal to assess whether the government had established an interoperability framework to bring uniformity among government systems. We found that the government of Nepal had recognized its importance and had established an interoperability framework. The final draft of the e-government interoperability framework, known as the Nepal E-Government Interoperability Framework (NeGIF), was introduced in 2010. The government defined interoperability in three dimensions: business processes and organizational interoperability, information or semantic interoperability, and technical interoperability. The government introduced various standards and guidelines for applications, databases, networks, security and firewalls, document types, and all other technological aspects for all government departments and agencies. All government agencies and departments must follow these standards and guidelines while developing their systems. In addition, the Nepali government had developed its enterprise architecture (EA) framework which defined different components of the government, and how sub-architectures and government systems should be designed to achieve interoperability.

Activity 3: Identify integration platform

Some of the critical factors in achieving the integration stage of streamlined e-government services are cost and technology. Physical integration of e-government systems was becoming complex as many government offices in rural areas did not have access to reliable internet connectivity. Therefore, as defined by the maturity model and lessons learned from the previous case, we put forward a cloud-based solution for the integration and hosting of new applications.

Firstly, we conducted a cost-benefit analysis to compare the costs of existing e-government implementation and integration methods with cloud-based e-government implementation and 
integration. We aimed to analyze how much the department could save by adopting a cloud platform for its computing needs, and to deliver e-government services. We used the cost-benefit analysis template as shown in Figure 6, designed for the previous study while performing the implementation of the cloud-based framework.

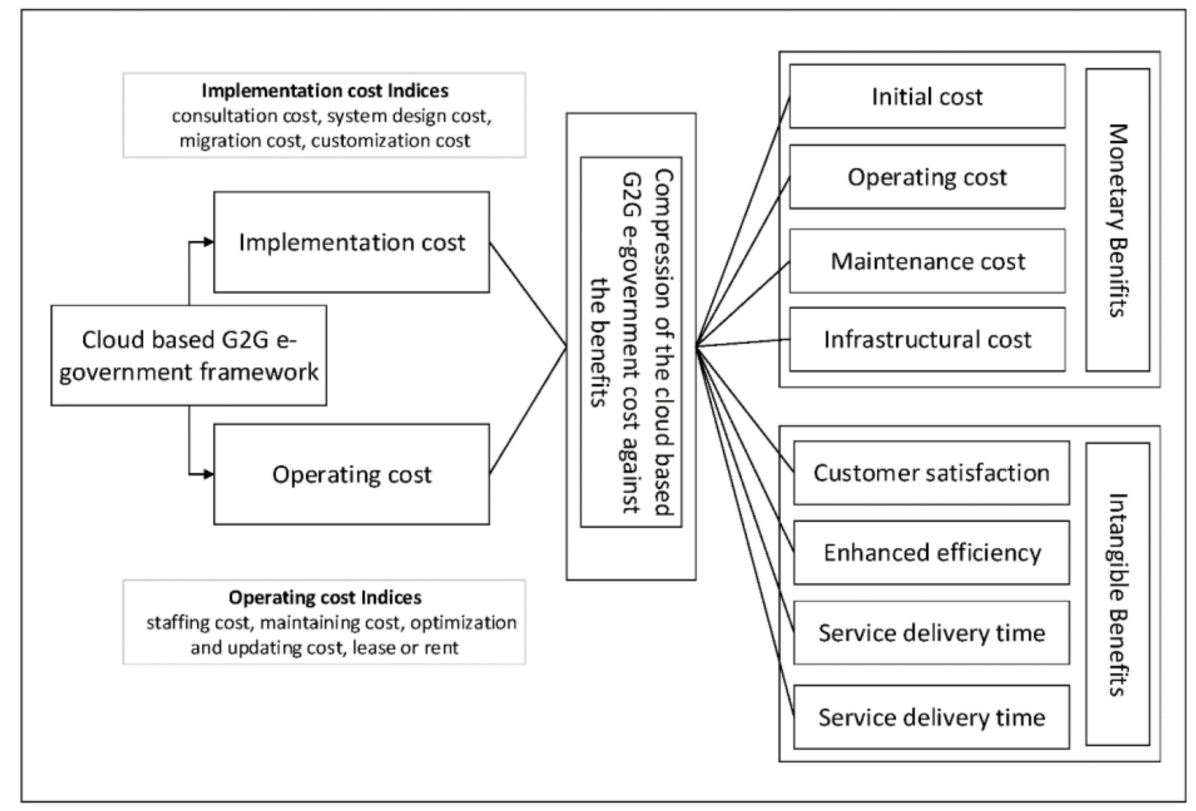

Figure 6. Cost-benefit analysis for adopting a cloud-based framework (Joshi et al. [39]).

We studied government accounts to determine expenditure of procuring, managing, and operating the e-government systems. We found that the department was allocated a budget every fiscal year for the infrastructure and enhancement of information and communication technology. The budget covered procurements of hardware and software, salaries of technical staff, training expenses, maintenance costs of hardware, the internet lease, and server co-location. We summed the amount that the department spent in one year on information and communication technology, and compared that with the cost the government would incur upon adopting a third-party cloud-computing platform to implement and integrate the existing e-government system. We found that the government would be able to significantly reduce the cost by adopting a cloud-computing platform.

Secondly, we compared the time and human resources the department would require to integrate various data sources using traditional integration technology with cloud-based integration. We found that many of the government offices and departments in rural areas were still facing connectivity problems, with physical networking between databases getting increasingly complex and time consuming. Despite the government's efforts to connect rural government offices, it seemed that the government would require a lot more time to accomplish connectivity. On the other hand, the migration of databases located in various offices, and their integration into a cloud would be achieved in less time. This integrated database would be accessible by any office at any time. This provided a clear picture of how the government could save time and cost by adopting a cloud-based implementation and integration of e-government services.

\section{Adoption Stages 1-2: Enhance Technical Skill and Trust}

Technical know-how among users is the most desirable condition to achieve citizen participation. We conducted two technical workshops on how to use government services, and two seminars on the benefits of using e-government services. The workshops were conducted by the IT staff responsible for e-government services. Participants included government employees from local government offices, and residents invited through the distribution of leaflets. Workshop participants were given 
in-depth training on how to use the services. The participants were distributed leaflets providing basic information about the government portal, names of various government services available online, and contact details of the help and support team.

The seminars were organized by government officials for residents to convey the e-government initiatives taken by the government, the available e-government services, the benefits of those services, and the future plan. The seminars were informative, with an hour of interactive question-and-answer sessions conducted at the end, for the benefit of the participants. Their opinions were noted by government officials. The workshops and seminars proved a milestone in increasing the know-how of participants, while the opinions and concerns of participants helped officials rethink how the offered services could be realigned with the citizens' needs. Government officials found the workshops and seminars to be an effective way of increasing the know-how among the people, and decided to organize them more frequently at the local level.

\section{Adoption Stage 3: Establish the Delivery Channels}

The final task performed to achieve streamlined e-government services was to establish their delivery channels. We analyzed the probability of using various delivery channels defined by the proposed model in the given context. As the adoption of the delivery channels was subject to availability and feasibility, those adopted in this context may not be appropriate for other countries. We assessed various delivery channels, such as telecenters and government kiosks, which had been successfully adopted by other developing countries, such as India and Pakistan. After a brainstorming session among participants, we found that these delivery channels did not fit in the Nepali context. Therefore, after discussions with government officials, we all agreed that the most feasible option was to use rural municipalities and local libraries as delivery channels for e-government services. The decision to adopt rural municipalities and local libraries as delivery channels was made based on the feedback we received from participants in a previously-conducted seminar. Most of the participants demonstrated concerns in relation to the reliability of e-government services provided through kiosks, due to a lack of the technical skills required to operate the kiosks, and potential risks of exposing sensitive information in telecenters. Therefore, the rationale for selecting rural municipalities and local libraries was to achieve efficiency in government services while assuring users of the integrity of their confidential information.

\subsubsection{Observations}

We made several observations, and recorded the opinion of participants during the case study, which was presented using content analysis. Content analysis is used in qualitative research to categorize, classify, and summarize qualitative data (Neuendorf [40]). We found that streamlined services could be achieved by adopting the proposed model. We also noticed that the transaction stage could not be completely achieved without the integration of government departments. Therefore, the integration stage coming before the transaction stage, as suggested by the proposed maturity model, was justified. We summarized the observations as described below.

i. Detailed assimilation processes minimized risk and provided better strategies of implementing e-governments.

During the case study, we had many formal and informal discussions in relation to the processes and activities defined by the maturity model. We also had discussions about the four-stage maturity model that was initially adopted by the Nepali government in order to develop its e-government projects. We found that, although the Nepali government had already performed many activities and achieved the goal defined by the proposed model, it had not been able to achieve its aim in the absence of a detailed assimilation plan. The case-study participants were impressed by the detailed activities and processes defined by the proposed maturity model. They found the detailed activities very helpful in understanding the requirement for achieving each level of maturity, and for planning the next level. " ... the activities defined by the model are supportive to the development of 
appropriate strategies to implement e-government services, and would save us time and effort" (participant 1, e-government employee). Case-study team members from the government IT department thought that the systematically arranged activities under each stage in the proposed model would bring more clarity for the government. "..the activities defined by the model are useful and support the government to pre-plan for the next stage. The pre-defined activities also save the government a lot of time that is required when designing implementation strategies" (participant 2, government IT expert). One government employee stated that the naming of the stage, based on the service maturity rather than the technological maturity, supported the government in the comparisons between the project outcome and the aim of the e-government. Although the service maturity was the result of the applied technology, they found it easy to understand, in terms of the service delivery. "... the stage names, based on the service maturity, will help the government assess their project based on the accomplishment of the service, and help the government explain the achievement to various stakeholders in non-technical terms" (participant 4, government employee). The above findings positively supported the first hypothesis, which said that maturity models should have detailed assimilation processes to support the government in designing sustainable e-government services.

ii. Streamlining services through integration improved efficiency.

We found that various government departments adopted a government-to-citizen approach to the e-government, where certain services (e.g., the download of application forms, application status checks, the checking of exam results, etc.) were offered by specific departments. However, no services were effective as they required users to visit government offices to complete transactions. The case-study findings showed that the proposed model supported the government in achieving streamlined government services within the department. The integration of various e-government systems located in various geographical locations was done so as to form a consolidated system that allowed rural municipalities to deliver various government services using less time and effort. The case-study participants agreed that efficiency of government processes was achieved through streamlined e-government services. The manual processing of information was eliminated, enabling government employees in rural municipalities to make immediate decisions, and to process user requests in real time. This resulted in more efficient work. Furthermore, the integration platform as a service performed well, and it was found that the government would save costs, and would require less effort to integrate and implement e-government services using a cloud-computing platform. However, the availability of the cloud-computing resources and their reliability in the context of Nepal remain an issue. Therefore, the government needs to take an initiative to establish a cloud infrastructure, or to develop appropriate laws and policies in relation to the use of private or public clouds for the delivery of e-government services. Having said that, the cost-benefit analysis showed that the cost of establishing the cloud was expensive, making it less feasible in the context of developing countries. However, the overall operating cost once the cloud infrastructure is established was found to be very low in comparison to the cost of traditional e-government projects. Regardless of the issues in the integration of government systems, it is desirable that integration should be done before the transaction stage begins, so as to streamline e-government services. One of the aspects we considered for sustainable e-government services was efficiency, in terms of cost, time, and efforts. This was achieved by adopting the proposed model. Therefore, the second hypothesis, which stated that the proposed model supported governments in delivering streamlined services resulting in their sustainability, was proven true.

iii. Use of state-of-the-art technology was essential for sustainable e-government services in developing countries.

We observed that the use of state-of-the-art technology to implement and deliver e-government services increased government productivity, while allowing governments to reach a wider number of e-government service users. The proposed maturity models suggested various activities at various stages that emphasized adopting state-of-the-art technology (e.g., having a social media presence in the initial stage, use of shared computing resources among government departments through 
cloud-computing platforms and the like, use of cloud-based integration for streamlining services, and use of e-wallets for transaction processing). Moreover, the use of state-of-the-art technology in e-government activities was found to be cost-effective in comparison to older technologies, supporting the sustainability of e-government services. The unofficial Facebook page that was set up as a part of the case study, for the administrative office of the district of Kailali, received more than 20,000 likes over the course of a week. Users wrote their views, requests, and complaints about government services on the page. Government officials found it very useful in designing citizen-oriented approaches to service delivery. Furthermore, it made communication more transparent and clear between government officials and citizens. Finally, the integration of the databases of two administrative offices in the districts of Kailali and Kanchanpur was achieved through the use of cloud-based integration, resulting in greater efficiency.

\subsection{Survey Study}

The aim of the survey was to analyze the adoption determinants from a sustainability perspective. The survey took place in the same geographical location as the case study.

\subsubsection{Hypothesis}

We proposed two hypotheses for the survey. The hypotheses were developed by considering the adoption determinants defined for sustainable e-government services.

Hypothesis 3. Agile accessibility to e-government services will acquire wider adoption by users.

Hypothesis 4. Increased trust and awareness of e-government services will have a positive impact on the decisions of users to adopt them.

\subsubsection{Data Collection and Analysis}

We used a questionnaire for data-collection purposes. The questionnaire consisted of both open and closed questions, and took approximately $45 \mathrm{~min}$ to complete. A sample of questions asked is listed in Appendix A. The structure of the questionnaire was based on the adoption determinants. Four general, and fourteen objective questions were asked with the intention of acquiring the opinions and thoughts of the participants. A psychometric scale ranging from 1 to 7 was utilized to ascertain the participants' views on various aspects. To establish its validity, the designed questionnaire was then tested on five colleagues and researchers in the field. The layout of the questionnaire was changed as deemed appropriate, based on the feedback of the pilot test. Initially, questionnaires were distributed to selected participants with a deadline of two weeks. However, some participants did not complete the questionnaires, and in those cases, the first author and his local team (two university students) collected the responses through means of an interview with the participants in question. The collected data was analyzed using both qualitative and quantitative methods. Our analyses considered participants' own judgment, and their views regarding general e-government services for a sustainable approach to e-governments. We implemented various data analyses, such as regression analysis for quantitative data, and a deductive approach to qualitative data. Regression analysis was performed to determine the dependency of the intention to adopt e-government services on the proposed hypothesis regarding agile accessibility, trust, and awareness.

\subsubsection{Survey Context}

Nepal, one of the developing countries in South Asia, was selected for the survey. The Nepali government initiated the electronic government project in 2008 with the aims of minimizing corruption and better aligning government services to meet the needs of stakeholders. Although it was quite some time since the plan was announced, only a few projects had been completed thus far, among them 
the Nepali government's tax payer's portal, the portal for business licenses, and a service for passport applications. However, several constraints, such as access to technology, quality of service, and awareness and trust limited citizen participation in these e-government activities. The survey was conducted on 200 university students and 100 local residents of a city, both of whom were relatively familiar with technology. Participants were at least 18 years old, had basic IT skills, and had completed secondary education. We considered participants who had recently made passport applications, and had used the online service offered by the government. Stratified random sampling was employed to select the sample size. Stratified random sampling is used when there are multiple subsets or groups within a population, allowing sample sizes to proportionately represent the population. In total, 250 responses were received, of which 245 were valid. Five questionnaires were discarded as invalid (not completed or not answered correctly). As such, 245 questionnaires were used for the final analysis. Table 2 shows the number of respondents to the survey.

Table 2. Survey respondent statistics.

\begin{tabular}{cc}
\hline Description & Number \\
\hline Total number of participants & 300 \\
University students & 200 \\
Residents & 100 \\
Valid questionnaire & 245 \\
Invalid questionnaire & 5 \\
\hline
\end{tabular}

\subsubsection{Survey Findings}

The survey findings are presented in two separate sections as we used two separate approaches to data analysis.

\section{Participants' Opinions on Sustainable E-Government Services}

The subjective questionnaire provided us with rich insight into users' opinions on sustainable e-government services. Frequency analysis brought forward some interesting findings on the use of e-government services and the access to the ICT tools, prior to the proposed model being implemented.

Among the various factors which influence users' behavior and their intentions to adopt the electronic government, accessibility to e-government services emerged as the most critical factor (see Table 3). Only 20 participants of the 245 owned a computer, while 80 participants owned smart phones. Only 45 participants had access to the internet, with 20 participants knowing about e-government services. Based on only a few people having access to the technology, it is not unreasonable to think that this is the primary reason as to why adoption of e-government services is unsuccessful in developing countries. After the implementation of the proposed model, the participants' opinions changed significantly. The variance in the adoption of the e-government prior to implementation and after implementation of the model is presented in Table 4.

Table 3. Participants using ICT tools and having awareness.

\begin{tabular}{cc}
\hline Description & Numbers \\
\hline Participants own computer & 20 \\
Participants own smart phone & 80 \\
Participants know about e-government services & 20 \\
Participants have access to the internet & 45 \\
\hline
\end{tabular}


Table 4. Variation in the adoption of e-government services.

\begin{tabular}{ccc}
\hline $\begin{array}{c}\text { Adopted the } \\
\text { E-Government (Yes/No) }\end{array}$ & $\begin{array}{c}\text { Before the Implementation of } \\
\text { the Maturity Model }\end{array}$ & $\begin{array}{c}\text { After Implementation of the } \\
\text { Maturity Model }\end{array}$ \\
\hline YES & 20 & 197 \\
NO & 225 & 48 \\
\hline
\end{tabular}

We organized the findings from the subjective answers into three different themes-agile accessibility, trust/awareness, and quality of services. We identified some keywords, such as lack of trust, lack of access to technology, lack of awareness, and poor quality of information, which were frequently used in the responses. These keywords were used as categories of user opinions across the aforementioned themes for analysis.

- Impact of agile accessibility on the adoption of e-government services

The first determinant for the viable e-government maturity model from a citizen's perspective was agile accessibility to e-government services. We argued in the proposed model that agile accessibility would encourage a wider number of citizens to use and adopt e-government services in developing countries. The survey findings supported the argument and showed that a lack of access to technology (e.g., internet, computers, smart phones, etc.) negatively impacts users' intentions to adopt e-government services. The participants agreed that because e-government services were now more easily accessible, they were more likely to use them. Most of the participants agreed that the passport application and validation processes took less time. Various access points for the delivery of e-government services (local government offices and libraries) made it easy to access e-government services for participants who did not have access to a computer or the internet. They further suggested that an increase in the number of delivery channels (e.g., mobile e-government service stations, kiosks, and community centers) would be highly effective in the local community.

- Impact of awareness and trust on citizen participation in e-government activity

The second determinant that played a crucial role in designing the viable e-government maturity model for sustainable e-government services was the awareness and trust among citizens of e-government services. The trust of the online transaction system had a huge impact on citizens' intentions of using the electronic government. Prior to the implementation of the maturity model, participants found that, most of the time, online transactions returned as invalid, meaning the process had to be restarted. In most cases, they completed the service by visiting the government office. Moreover, some of the (age group of 45-55 years old) participants had strong ties with government officials, with whom they had built good relationships over the years, and with whom they felt more confident when completing the services in person. Participants found that government initiatives to build trust through various campaigns and through the introduction of various laws ensuring the security and privacy of online transactions were significant. Furthermore, ICT workshops conducted by the government in the local community were also helping to develop trust among people of using e-government services. An online presence through social media (a Facebook page for the local government body) acquired huge popularity from users. Participants found that government Facebook pages and Twitter accounts were great sources of information on government activities. However, participants raised concerns in relation to the content and its quality on the government portal. Some of the participants found that poor quality of e-government services discouraged them from using those services. They stressed that trust came from the quality of service that the government offered.

- Quality of service

Quality was defined as the quality of information, its relevance, response time, and the availability of help and support. However, this was lacking in the context of developing countries. Participants 
found that government websites were not compatible with smart phones and tablets. The websites were designed to be viewed on certain devices, with browsers limiting non-computer users from accessing the services. Participants agreed that device-independent and smart-phone-friendly designs would encourage users to access online services. Some of the participants found that a lack of language selections on the government website made it hard to use. Most of the computing terms were in English, and when translated into the local language (Nepali), confused users. For example, the government's tax payer's portal only accepted the Nepali language when inputting user data. Participants agreed that allowing language selection would help users use their preferred languages. However, they found that the web applications were complex as abbreviations used on the website were not properly described, contents were poorly maintained and managed, and the interface was not user-friendly. Some participants stopped using the e-government web application after a couple of times as there was no help available when needed. The websites neither offered technical support, nor was there any dedicated customer support available. Participants were more likely to use e-government services if these issues were addressed.

\section{Validation of the Hypothesis}

We documented and categorized responses using the GNU PSPP 1.0 software for statistical data analysis. A multiple regression analysis was performed to examine the impact of independent variables (agile accessibility and trust/awareness) on the dependent variable (users' intentions of adopting e-government services). Table 4 shows the results of the regression analysis.

We analyzed a total of 245 valid responses received from survey participants. The analyzed cases resulted in significant findings that supported the hypothesis. As shown in Table 5, the adjusted $\mathrm{R}$-squared value represented the level of variation in the dependent variable upon changing the independent variable. The regression analysis showed that the adjusted R-squared value was $95.8 \%$, proving the decision to adopt e-government services was highly dependent on agile accessibility, trust, and awareness, whereas the remaining $4.2 \%$ of decisions were influenced by other factors.

Table 5. Initial regression analysis.

\begin{tabular}{cc}
\hline \multicolumn{2}{c}{ Regression Analysis } \\
\hline Adjusted R-Squared & 0.95863531 \\
Standard Error & 0.37817496 \\
Observations & 245 \\
\hline
\end{tabular}

The regression analysis presented in Table 6 shows that all three independent variables-agile accessibility $(p<0.005)$, trust $(p<0.009)$, and awareness $(p<0.009)$ - had significant values. The variables were considered significant, and as having an impact on the dependent variable when the $p$-value was lower than 0.05 . Thus, the retrieved $p$-values of less than 0.05 proved the hypothesis of agile accessibility, trust, and awareness impacting users' decisions to adopt e-government services. The analysis also suggested that agile accessibility had the most significant impact $\left(R^{2}=0.164\right)$ on user decision, followed by awareness $\left(R^{2}=0.139\right)$, and trust $\left(R^{2}=0.078\right)$.

Table 6. Further regression analysis.

\begin{tabular}{ccccc}
\hline & $\mathbf{R}^{\mathbf{2}}$ & Standard Error & $\boldsymbol{t}$-Statistic & $\boldsymbol{p}$-Value \\
\hline Intercept & 0.811 & 0.36879 & 2.20169 & 0.028 \\
Agile accessibility & 0.164 & 0.058152 & 2.82966 & 0.005 \\
Trust & 0.078 & 0.030195 & 2.605863 & 0.009 \\
Awareness & 0.139 & 0.053355 & 2.606809 & 0.009 \\
\hline
\end{tabular}




\subsection{Validity}

There is always a risk of expectancy bias in survey and case-study results, and we tried reducing it. As such, we trained university students and used them to conduct the survey, as they were not directly related with the research. For any empirical investigation, it is necessary to ensure the availabilities of resources and participants, and we confirmed these before initiating the investigation. Participants were selected based on specific criteria so that they could understand the questions. This reduced the threat of asking the wrong questions, validating the constructs. We collected data from multiple sources for both the survey and the case study in an effort to reduce the effects of interpretation of a single data source. However, Nepali cultural bias and lack of generalization could have been introduced as external validity. However, we compared our study results with other studies so as to generalize our findings and reduce this bias.

\section{Final Observations}

This section provides a brief discussion on how the findings from the two methods of evaluation support the validity of the proposed model contributing to the design of sustainable e-government services. To validate the new maturity model, we proposed four hypotheses, two from the perspective of the implementation of e-government services, and two from the perspective of their adoption. The hypotheses were designed to test whether the defined determinants contributed in the design of sustainable e-government services. The tested determinants (agile accessibility, a detailed assimilation process, streamlined services, trust, and awareness) were incorporated into the new maturity model. We categorically discuss the test results below.

We have argued in the first hypothesis that the detailed assimilation process provided by the proposed maturity model will contribute in developing sustainable e-government services. The case-study results showed that the stages of e-government implementation and their respective processes defined by the new maturity model were simple, and provided a list of detailed activities required to achieve each stage. Government officials found that the detailed processes saved them significant time, which was required when assessing and implementing certain services. The predefined set of activities better prepared governments to design strategies to implement e-government services. Along with saving time, government officials also found that the predefined set saved significant cost and effort. Therefore, this proved that the inclusion of detailed assimilation processes in the maturity model supported the design of sustainable e-government services.

We argued that streamlining e-government systems would support for sustainable e-government service delivery in the second hypothesis. One of the critical problems we found in existing e-government maturity models was the arrangement of stages. We argued that the integration of e-government systems should be done prior to the transaction stage, so as to provide streamlined services to users in developing countries. The findings showed that the integration of the district and local offices contributed to providing seamless and streamlined services to users. This saved the government time in delivering services while acquiring increased satisfaction. Particularly, the integration of government systems eliminated the manual paper-based validation processes that happened in government offices. Therefore, new arrangement of the implementation stage proved that the government could deliver streamlined services by adopting the new model.

The third hypothesis stated that agile accessibility to the e-government services should be ensured to acquire wider acceptance from the user. We tested this hypothesis by employing regression analysis. Since the decision to adopt e-government services deals with human behavior, we considered the adoption determinant of agile accessibility as an independent variable that impacted or influenced users' intentions of adopting e-government services. The regression analysis retrieved a predictive value for agile accessibility of less than 0.15 , which was significant. Meanwhile, variation in patterns of the use of e-government services showed that more users adopted e-government services after the new model was implemented. Thus, this proved that agile accessibility to e-government services acquired wider adoption by users. 
Hypothesis 4 considered trust and awareness as one of the critical determinants that impact on the user decision of e-government services adoption. Regression analysis also showed that trust and awareness played crucial roles in the decisions of users to adopt e-government services. The $p$-values for both trust and awareness were lower than 0.15 , which was considered significant. The subjective questions also showed users' opinions that the government's efforts to build trust and awareness helped them use e-government services. Therefore, this proved that trust and awareness contributed positively to users' decisions to adopt e-government services.

Therefore, both the case-study and survey findings proved that the incorporation of the aforementioned determinants in the new model contributed to the design of sustainable e-government services.

A new determinant (quality of services) emerged as an important contributor to the decision to adopt e-government services. Most of the participants expressed their opinions in relation to the quality of the portal and its content as making e-government service less attractive. They provided their opinions to the government in relation to the improvement in quality of e-government services. Therefore, we included the quality of services as the sixth determinant of the design of sustainable e-government services, which is presented in Figure 7.

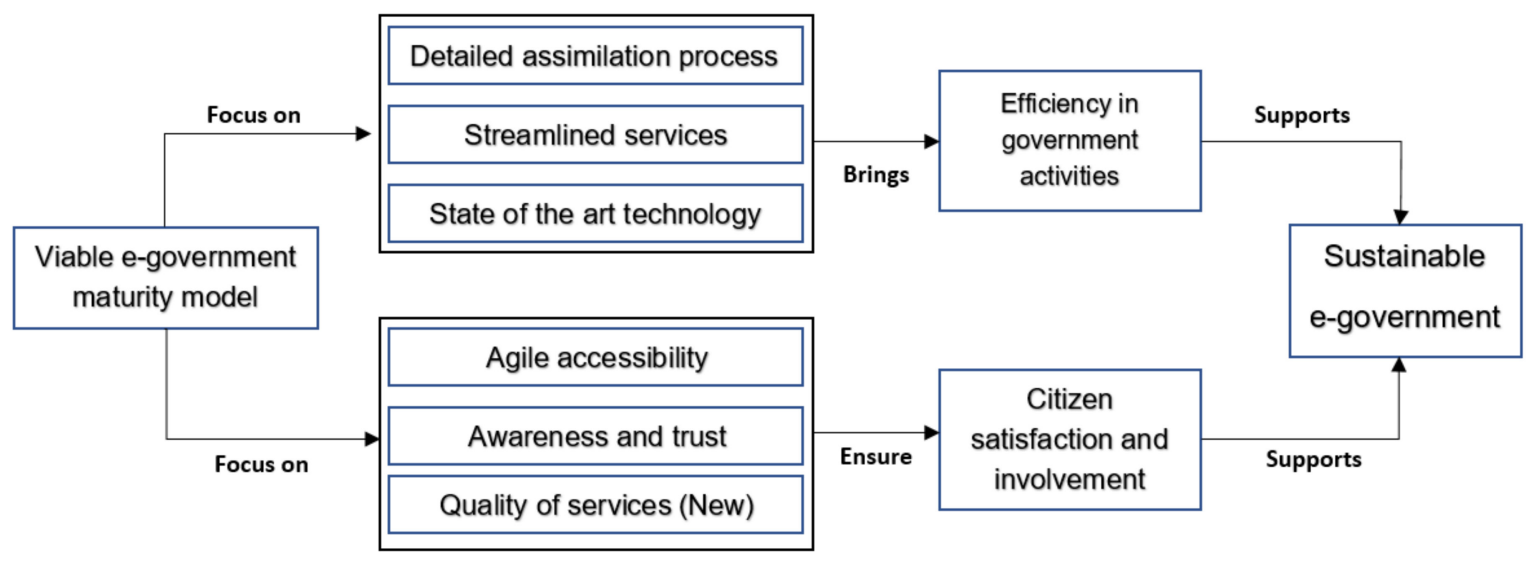

Figure 7. Revised determinants of the viable e-government maturity model.

\section{Conclusions}

This paper proposes an e-government maturity model for sustainable e-government services. We observed many limitations of existing e-government maturity models. Linear patterns of e-government developmental stages, a technology-centric nature, a lack of detailed processes, and a lack of state-of-the-art technology were some of the key issues found in the review. We found that a misalignment in the process of e-government project assimilation and in the e-government maturity model stages was caused by these limitations, resulting in unsustainable e-government services.

Therefore, considering the limitations of existing models, we defined a number of determinants, for a viable e-government maturity model, required to develop sustainable e-government services. Based on the determinants, we developed a new model and evaluated it from the perspective of sustainability of e-government services. The key feature of the proposed model was the integration of the implementation and adoption stages in order to bring efficiency to government services, while aligning them with citizens' needs. The findings of the case study proved that the detailed assimilation processes and streamlined approaches to service delivery were the most desirable determinants for sustainable e-government services, from an implementation perspective. The proposed model supported government departments in efficiently initiating e-government services, and in achieving streamlined services. The findings from the survey supported the hypothesis which argued that the proposed adoption determinants were central to the sustainability of e-government services. The regression analysis was used to analyze the impact of the proposed determinants on the decisions of users to adopt e-government services. It showed that the determinants played crucial roles in encouraging users to adopt e-government services. Overall, 
these findings supported that sustainable e-government services could be achieved by adopting the proposed e-government maturity model.

Author Contributions: P.R.J. contributed to the design and development of the maturity model. S.I. contributed to the review of the existing literature and to the review of the whole paper. S.I. also assisted with the empirical investigation section. P.R.J. also set up and performed the case study and survey. Both authors reviewed and approved the manuscript.

Acknowledgments: We would like to acknowledge the government department and survey participants of Nepal. Conflicts of Interest: The authors declare no conflict of interest.

\section{Appendix A. Sample Survey Questions}

\section{Appendix A.1. Subjective Questionnaire}

Please provide your own view.

1. How often and what e-government services do you use generally?

2. What channels are available to you for accessing the e-government services?

- mobile

- own computer

- cyber café

- library

- other

3. In your opinion, what does the government need to do to make e-government services accessible and reliable for their sustainability?

\section{Appendix A.2. Closed Questions}

Please tick the most suitable number for your opinion. The number represents the scale of your opinion. $1=$ Strongly Agree, 2 = Agree, 3 = Neutral, $4=$ Disagree, 5 = Strongly Disagree.

\begin{tabular}{|c|c|c|c|c|c|c|}
\hline \multirow{2}{*}{ S.N } & \multirow{2}{*}{ Questions } & \multicolumn{5}{|c|}{ Scale } \\
\hline & & 1 & 2 & 3 & 4 & 5 \\
\hline \multicolumn{7}{|c|}{ Agile accessibility to the service } \\
\hline 1 & $\begin{array}{l}\text { E-government services are easily accessible to me and the people } \\
\text { who live around me. }\end{array}$ & & & & & \\
\hline 2 & $\begin{array}{l}\text { The current effort put in by the government toward the delivery } \\
\text { of e-government services is sufficient. }\end{array}$ & & & & & \\
\hline 3 & $\begin{array}{l}\text { The proposed delivery channels for e-government services are } \\
\text { useful and would enable me to access the services conveniently. }\end{array}$ & & & & & \\
\hline
\end{tabular}

\section{References}

1. Layne, K.; Lee, J. Developing fully functional E-government: A four stage model. Govern. Inf. Q. 2001, 18, 122-136. [CrossRef]

2. Reddick, C.G. A two-stage model of e-government growth: Theories and empirical evidence for US cities. Govern. Inf. Q. 2004, 21, 51-64. [CrossRef]

3. Fath-Allah, A.; Cheikhi, L.; Al-Qutaish, R.E.; Idri, A. E-government maturity models: A comparative study. Int. J. Softw. Eng. Appl. 2014, 5, 71-91.

4. Andersen, K.V.; Henriksen, H.Z. E-government maturity models: Extension of the Layne and Lee model. Govern. Inf. Q. 2006, 23, 236-248. [CrossRef]

5. Kim, D.Y.; Grant, G. E-government maturity model using the capability maturity model integration. J. Syst. Inf. Technol. 2010, 12, 230-244. [CrossRef]

6. Debri, F; Bannister, F. E-government stage models: A contextual critique. In Proceedings of the 201548 th Hawaii International Conference on System Sciences (HICSS), Kauai, HI, USA, 5-8 January 2015; pp. 2222-2231. 
7. Ibrahem Zahran, D.; Al-Nuaim, H.A.; Rutter, M.J.; Benyon, D. A Critical Analysis of M-Government Evaluation Models at National and Local Municipal Levels. Electron. J. e-Gov. 2015, 13, $28-42$.

8. Howard, M. E-government across the globe: How will 'e' change government. e-Government 2001, 90, 80.

9. Baum, C.; Di Maio, A. Gartner's Four Phases of E-Government Model. Available online: http:/ /www.gartner.com/ /id=317292 (accessed on 10 October 2017).

10. Chandler, S.; Emanuels, S. Transformation not automation. Proceedings of 2nd European Conference on e-Government 2002, Oxford, UK, 1-2 October 2002; pp. 91-102.

11. West, D.M. E-government and the transformation of service delivery and citizen attitudes. Public Admin. Rev. 2004, 64, 15-27. [CrossRef]

12. Hiller, J.S.; Bélanger, F. Privacy strategies for electronic government. e-Government 2001, 200, 162-198.

13. Moon, M.J. The evolution of e-government among municipalities: Rhetoric or reality? Public Admin. Rev. 2002, 62, 424-433. [CrossRef]

14. Shahkooh, K.A.; Saghafi, F.; Abdollahi, A. A proposed model for e-Government maturity. In Proceedings of the 3rd International Conference on 2008 Information and Communication Technologies: From Theory to Applications, Damascus, Syria, 7-11 April 2008; pp. 1-5.

15. Siau, K.; Long, Y. Synthesizing e-government stage models-A meta-synthesis based on meta-ethnography approach. Ind. Manag. Data Syst. 2005, 105, 443-458. [CrossRef]

16. Wescott, C.G. E-government in the Asia-pacific region. Asian J. Polit. Sci. 2001, 9, 1-24. [CrossRef]

17. Deloitte Consulting. Deloitte Research, Deloitte $\mathcal{E}$ Touche and Deloitte Consulting at the Dawn of e-Government: the Citizen as Customer; Deloitte Consulting: New York, NY, USA, 2000.

18. The World Bank. A Definition of E-Government; The World Bank: Washington, DC, USA, 2003.

19. Coursey, D.; Norris, D.F. Models of e-government: Are they correct? An empirical assessment. Public Admin. Rev. 2008, 68, 523-536. [CrossRef]

20. Karokola, G.; Yngström, L. Discussing E-Government Maturity Models for the Developing World-Security View. In Proceedings of the ISSA 2009 Conference, Johannesburg, South Africa, 6-8 July 2009; pp. 81-98.

21. Lee, J. 10-year retrospect on stage models of e-Government: A qualitative meta-synthesis. Gov. Inf. Q. 2010, 27, 220-230. [CrossRef]

22. Abdelghany, H.; El-Bastawissy, A.; Osman, M. E-Government multi-layers Maturity Model. In Proceedings of the 2016 12th International Computer Engineering Conference (ICENCO), Cairo, Egypt, 28-29 December 2016; pp. 83-92.

23. Szeremeta, J. Benchmarking e-government: A global perspective. In Proceedings of the International Congress on Government Online, Ottawa, ON, Canada, 25-27 November 2002.

24. Rana, N.P.; Dwivedi, Y.K.; Williams, M.D.; Weerakkody, V. Investigating success of an e-government initiative: Validation of an integrated IS success model. Inf. Syst. Front. 2015, 17, 127-142. [CrossRef]

25. United Nation. E-Government for the Future We Want; United Nations E-Government Survey; United Nation: New York, NY, USA, 2014.

26. Tripathi, R.; Gupta, M.P. Evolution of government portals in India: Mapping over stage models. J. Enterp. Inf. Manag. 2014, 27, 449-474. [CrossRef]

27. Supriyanto, A.; Mustofa, K. E-gov readiness assessment to determine E-government maturity phase. In Proceedings of the 2016 2nd International Conference on Science in Information Technology (ICSITech), Balikpapan, Indonesia, 26-27 October 2016; pp. 270-275.

28. Hollenstein, H. Determinants of the adoption of Information and Communication Technologies (ICT): An empirical analysis based on firm-level data for the Swiss business sector. Struct. Chang. Econ. Dyn. 2004, 15, 315-342. [CrossRef]

29. Shareef, M.A.; Kumar, V.; Kumar, U.; Dwivedi, Y.K. E-Government Adoption Model (GAM): Differing service maturity levels. Gov. Inf. Q. 2011, 28, 17-35. [CrossRef]

30. Napitupulu, D.; Sensuse, D.I. Toward maturity model of e-Government implementation based on success factors. In Proceedings of the 2014 International Conference on Advanced Computer Science and Information Systems (ICACSIS), Jakarta, Indonesia, 18-19 October 2014; pp. 108-112.

31. Almarabeh, T.; AbuAli, A. A general framework for e-government: Definition maturity challenges, opportunities, and success. Eur. J. Sci. Res. 2010, 39, 29-42.

32. Aichholzer, G. Scenarios of e-Government in 2010 and implications for strategy design. Electron. J. E-Gov. 2004, 2, 1-10.

33. Bertot, J.C.; Jaeger, P.T.; Grimes, J.M. Using ICTs to create a culture of transparency: E-government and social media as openness and anti-corruption tools for societies. Gov. Inf. Q. 2010, 27, 264-271. [CrossRef] 
34. Rowley, J. E-Government stakeholders-Who are they and what do they want? Int. J. Inf. Manag. 2011, 31, 53-62. [CrossRef]

35. Curry, E.; Donnellan, B. Understanding the maturity of sustainable ICT. In Green Business Process Management; Springer: Berlin/Heidelberg, Germany, 2012; pp. 203-216.

36. Riggins, F.J.; Dewan, S. The digital divide: Current and future research directions. J. Assoc. Inf. Syst. 2005, 6, $298-337$. [CrossRef]

37. Cullen, R. Addressing the digital divide. Online Inf. Rev. 2001, 25, 311-320. [CrossRef]

38. Gillham, B. Case Study Research Methods; Bloomsbury Publishing: London, UK, 2000.

39. Joshi, P.R.; Islam, S.; Islam, S. A Framework for Cloud Based E-Government from the Perspective of Developing Countries. Future Internet 2017, 9, 80. [CrossRef]

40. Neuendorf, K.A. The Content Analysis Guidebook; Sage: Los Angeles, CA, USA, 2016.

(C) 2018 by the authors. Licensee MDPI, Basel, Switzerland. This article is an open access article distributed under the terms and conditions of the Creative Commons Attribution (CC BY) license (http://creativecommons.org/licenses/by/4.0/). 